\title{
INFLUENCE OF INTERLAYER MACROSTRESS ON OXIDATION OF SHELL TUBES FROM Zr-BASED ALLOYS
}

\author{
Margarita Isaenkova ${ }^{\mathrm{a}^{*}}$, Yuriy Perlovich ${ }^{\mathrm{b}^{*}}$, Pavel Medvedev, \\ Olga Krymskaya, Soe San Thu \\ National Research Nuclear University "MEPhl”, Moscow, Russia \\ aisamarg@mail.ru, byuperl@mail.ru
}

Keywords: shell tubes, Zr-based alloys, oxidation, texture layering, tensile stress.

\begin{abstract}
Shell tubes from Zr-based alloys are responsible construction elements of atomic reactors. Under exploitation these tubes undergo to oxidation, which can become a reason for their cracking. Inevitable texture layering arises by rolling of tubes due to different values of the Q-factor, calculated for inside and outside tube layers. Therefore these layers are characterized by different texture Kearns parameters and, correspondingly, by different thermal expansion. As a result, tensile tangential macrostress operates between layers and oxygen diffusion into tube intensifies.
\end{abstract}

\section{Introduction}

Application of precise contemporary X-ray methods by study of shell tubes from Zr-based alloys permitted to reveal a number of structure features, able to quicken diffusion of oxygen into the matrix. First of all this relates to inhomogeneity of the crystallographic texture through the tube wall, arising due to different values of Q-factor, calculated for layers, which adjoin to inside and outside surfaces of tube. Q-factor is the major technological parameter of the tube rolling and determines its texture to a considerable extent [1]. It is equal to the ratio of reduction by tube wall $\Delta \mathrm{t} / \mathrm{t}$ to reduction by its diameter $\Delta \mathrm{D} / \mathrm{D}$, where $\mathrm{t}$ - thickness of wall and $\mathrm{D}$ - diameter of tube. As $\mathrm{Q}$ factor increases, texture maxima in $\mathrm{PF}(0001)$ shift to the center of stereographic projection, coinciding with tube radial direction $R$ (here $\mathrm{PF}-$ pole figure).

Usually Q-factor is calculated, when starting from the thickness of whole tube wall. However if we distinguish in the tube at least two layers and determine for them values of Q-factor by assumption, that deformation through these layers is homogeneous, we would see that obtained values of Q-factor inevitably differ from each other. Though at the first approximation textures of these layers are visually similar, their corresponding integral Kearns parameters $f_{\mathrm{R}}, f_{\mathrm{T}}$ and $f_{\mathrm{L}}$, used for quantitative estimation of texture in tubes from Zr-based alloys and calculated as projections of the basal axes distribution on radial, tangential and axial directions of tube [2-3], prove to be somewhat different. Influence of this effect on corrosion behavior of shell tubes is considered in the given paper.

\section{Studied samples and methods of investigation}

Studied samples were cut out from several series of shell tubes, submitted to regular technological treatment. These samples were used by X-ray texture studies with application of the method [4]. At that electro-erosion cutting of tubes into separate segments and X-ray measurements of composite samples was used, followed by construction of direct $\mathrm{PF}(0001)$ and calculation of integral Kearns parameters. The similar fragments of the same tubes were saturated with hydrogen in the vapor-water atmosphere within an autoclave during 42 hours at $350^{\circ} \mathrm{C}$. Then cross-sections of tubes were studied using optical microscopy in order to reveal hydride particles [5]. 


\section{Experimental results and their discussion}

Results of tube texture analysis are presented in Fig. 1. At its left part (Fig. 1-a) a fragment of shell tube and ifs flat sections, studied by X-ray texture measurements, are depicted, whereas at its right part (Fig. 1-b) - results of measurements. From above the partial $\mathrm{PF}(0001)$ (with angular radius $80^{\circ}$ ) for the outward layer of tube with calculated Kearns parameters are shown, while from below - the same for the inward layer of tube. Further (Fig. 1-c) equatorial sections $R-T$ of PF(0001) for both layers are constructed. The difference of Kearns parameters for studied layers corresponds to the limiting sensitivity of the method for their determination [3], but the following example in Fig. 2 visually shows that this difference is sufficiently big for rise of essential tangential macrostress.

a
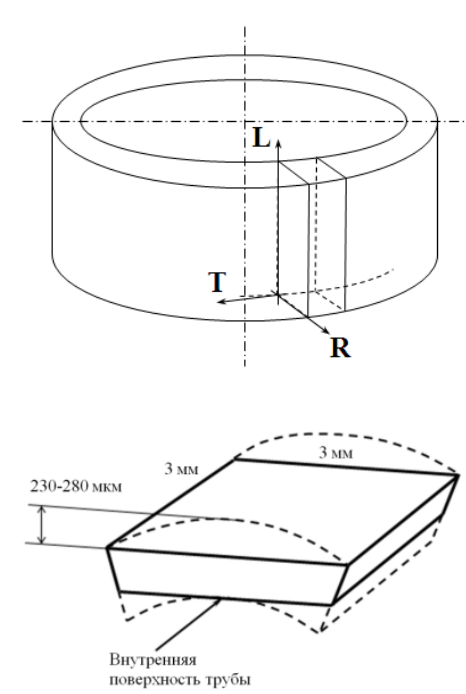

b

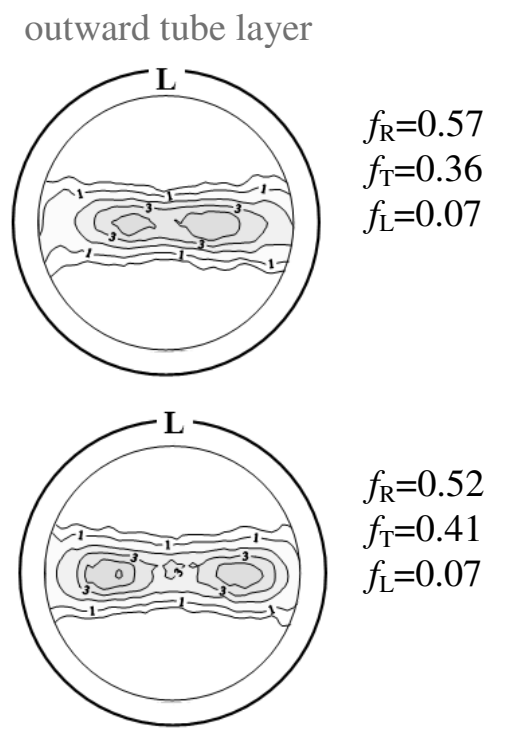

c

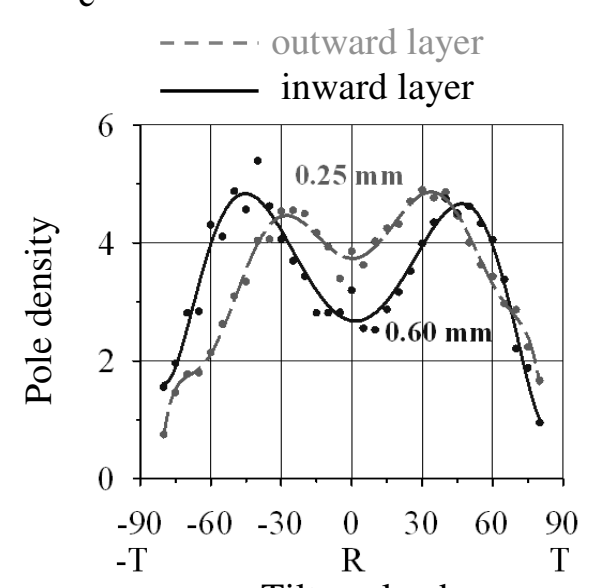

Tilt angle, deg.

inward tube layer

Fig. 1. Layer-by-layer inhomogeneity of shell tube texture

a

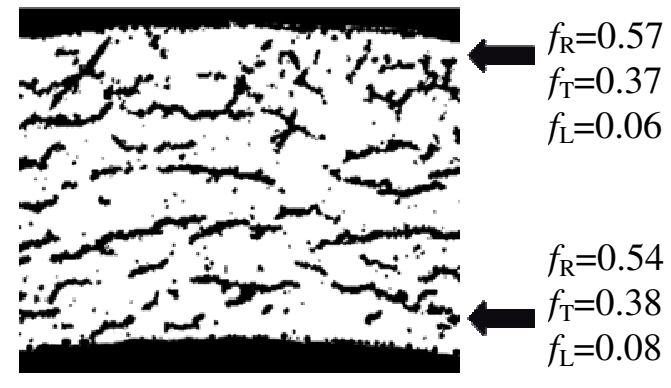

b

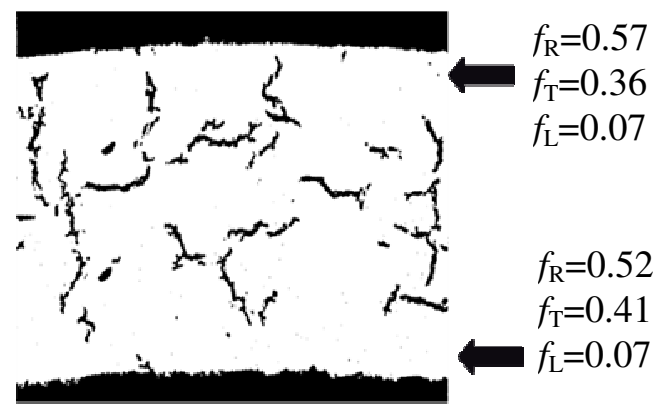

Fig. 2. Radially-oriented hydrides in the cross-section of tubes, submitted to heating up to $350^{\circ} \mathrm{C}$ in a autoclave

Coefficient of thermal expansion for any direction in tube, for example - for tangential direction $\mathrm{T}$, is connected with texture Kearns parameter $\mathrm{f}_{\mathrm{T}}$ in the following way: 


$$
\alpha_{\mathrm{T}}=\alpha_{c} f_{\mathrm{T}}+\alpha_{a}\left(1-f_{\mathrm{T}}\right)
$$

where $\alpha_{c}$ and $\alpha_{a}$ - coefficients of thermal expansion for $\alpha-Z r$ single crystal along axes $\mathrm{c}$ and a in its crystalline lattice. At that, Kearns parameter is calculated namely for the direction $T$ [3]. Mean values of coefficients $\alpha_{c}$ and $\alpha_{a}$ at $350^{\circ} \mathrm{C}$, found for a number of literature data [6], are equal to 5.5 $\mathrm{deg}^{-1}$ and $8.8 \mathrm{deg}^{-1}$, respectively.

Differences in thermal expansion of outward and inward layers along the tangential direction of tube at its exploitation temperature is a reason for rise in it of tangential macrostress. When the coefficient of thermal expansion $\alpha_{\mathrm{T}}$ of inward layer exceeds the analogous coefficient of outward layer, tangential tensile stresses operate at the outward layer of tube.

A reliable indicator of such stresses is rise of radially-oriented hydrides in the cross-section of tube, submitted to keeping in a autoclave (Fig. 2). By heating of tube up to $350^{\circ} \mathrm{C}$ solubility of hydrogen in $\alpha-\mathrm{Zr}$ increases more than by 10 times, and by next cooling this hydrogen enters in the composition of hydride phase, precipitating in tube in accordance with direction of operating macrostresses, when taking into account, that precipitation of hydrides is a mechanism of these macrostresses relaxation. Cross-sections of two shell tubes, presented in Fig.2, differ in arrangement of hydride phase precipitations. At that, in the first tube hydrides are situated along tangential direction, while in the second tube - along radial direction. Namely this circumstance confirms existence in the second tube of tangential macrostress before precipitation of the hydride phase, whereas the arrangement of hydrides in the first tube is conditioned by their habit planes, main of which are slip planes, in particular - prismatic ones [7-8]. The tangential macrostress, operating in the second tube, promotes penetration of oxygen inside the tube wall.

It is seen in Fig. 2-b, that under the influence of tangential macrostresses lamellar hydride particles take up radial positions, perpendicular to outward surface of tube, and coincide apparently with grain boundaries, having analogous orientations and being ways of active oxygen diffusion under operation of tangential macrostrsses. On the contrary, in the first tube (Fig. 2-a) by ant reason of shown there tangentially-oriented hydrides penetration of oxygen inside the tube wall is difficult because of absence of tangential stresses as well as transparent radial ways of oxygen diffusion, generated by these stresses.

Calculated deformations of shell tubes in the tangential direction as a result of their heating up to $350^{\circ} \mathrm{C}$ are presented in Table 1 in order to illustrate, how insignificant can be layer-by-layer texture inhomogeneity in tube, causing nevertheless a rise of essential macrostresses, responsible for precipitation of radially-oriented hydrides and promoting diffusion of oxygen inside the tube wall. Here $\varepsilon_{\mathrm{T}}$ - relative tangential deformation of the corresponding tube layer, and $\varepsilon_{\mathrm{T}}{ }^{\text {in }} / \varepsilon_{\mathrm{T}}{ }^{\text {out }}$ - the ratio of these values for inward and outward tube layers.

Comparison of deformation textures for inward and outward layers of tubes testifies, that in the second tube the relative tangential deformation of inward layer by $\Delta \mathrm{f}_{\mathrm{T}}=0,05$ already exceeds the deformation, responding to the yield stress.

Table 1. Thermal expansion of different layers of shell tube by its heating up to $350^{\circ} \mathrm{C}$

\begin{tabular}{|c|c|c|c|c|c|}
\hline $\begin{array}{c}\text { Sample } \\
\text { number }\end{array}$ & $\begin{array}{c}\text { Depth of layer, } \\
\mathrm{t}, \mu \mathrm{m}\end{array}$ & $f_{\mathrm{T}}$ & $\begin{array}{c}\alpha_{\mathrm{T}} 10^{-6}, \\
\mathrm{deg}\end{array}$ & \multirow{2}{*}{$\varepsilon_{\mathrm{T}, 10^{-3}} \varepsilon_{\mathrm{T}}^{\text {in }} / \varepsilon_{\mathrm{T}}{ }^{\text {out }}$} \\
\hline \multirow{2}{*}{1} & 250 & 0,37 & 6,721 & 2,2179 & \multirow{2}{*}{1,005} \\
\cline { 2 - 5 } & 600 & 0,38 & 6,724 & 2,2288 & \multirow{2}{*}{1,025} \\
\cline { 2 - 5 } 2 & 240 & 0,36 & 6,688 & 2,2070 & 2,2615 \\
\hline
\end{tabular}

When taking into account values $\varepsilon_{\mathrm{T}}^{\text {in }} / \varepsilon_{\mathrm{T}}$ out, presented in the last column, it becomes understandable, that by control of production the first tube was accepted as satisfying to technical conditions, whereas the second tube was rejected as spoilt. 


\section{Summary}

As obtained experimental data show, the layer-by-layer texture gradient is sufficient for noticeable variations of dimensional thermal changes in successive layers. In the case, when the coefficient of thermal expansion for the inward layer exceeds that for the outward layer, tangential tensile stresses operate at the outward tube surface. As a result, intensification of corrosion takes place.

\section{References}

[1] E. Tenckhoff, Deformation mechanisms, texture and anisotropy in zirconium and zircaloy, ASTM, Philadelphia, 1988.

[2] J.J. Kearns, Thermal Expansion and Preferred Orientation in Zircaloy. WAPD-TM-472, Report of Westinghouse Electric Corporation, Bettis Atomic Power Laboratory, Pittsburgh, PA (USA), 1965.

[3] M.G. Isaenkova, Yu.A. Perlovich, V.A. Fesenko, Current Methods of Experimental Construction of Textured Complete Direct Pole Figures from X-Ray Data, Industrial Laboratory, vol. 79, № 7-1 (2013) 25-32.

[4] Y. Perlovich, M. Isaenkova, Distribution of c- and a-Dislocations in Tubes of Zr Alloys, Metallurgical and materials transactions A, vol. 33A, No.3 (2002) 867-874.

[5] A.S. Zaimovskiy, A.V. Nikulina, N.G. Reshetnikov, Zirconium alloys in atomic energy, Energoizdat, Moscow, 1981 (in Russian).

[6] D.L. Douglass, The Metallurgy of Zirconium, Int. Atomic Energy, Vienna, 1971.

[7] Perovic V., Weatherley G.C., MacEwen S.R., Leger M. The influence of prior deformation on hydride precipitation in Zircaloy. - Acta metall. mater., 1992, v. 40, No.2, p. 363-372.

[8] Bai J.B., Prioul C., Francois D. Hydride embrittlement in Zircaloy-4 plate: Part I. Influence of microstructure on the hydride embrittlement in Zircaloy- 4 at $20^{\circ} \mathrm{C}$ and $350^{\circ} \mathrm{C}$. - Metallurgical and Materials Transactions A, 1994, v. 25A, p. 1185-1197. 